\title{
Bienes intelectuales de naturaleza sui generis: los conocimientos tradicionales del sector agrícola. Protección internacional
}

Yeney Acea-Valdés*

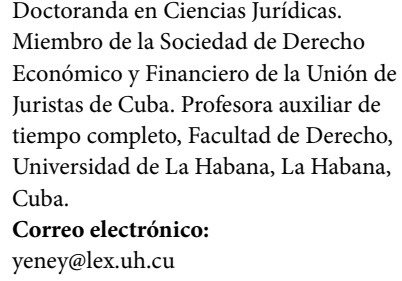

Doctoranda en Ciencias Jurídicas. Miembro de la Sociedad de Derecho Económico y Financiero de la Unión de Juristas de Cuba. Profesora auxiliar de tiempo completo, Facultad de Derecho, Universidad de La Habana, La Habana, Cuba.

Correo electrónico: yeney@lex.uh.cu

Recibido: 6 de junio del 2015

Aprobado: 3 de agosto del 2015

Cómo citar este artículo: Yeney AceaValdés. Bienes intelectuales de naturaleza sui generis: los conocimientos tradicionales del sector agrícola. Protección internacional. DIXI 22. Diciembre 2015. Pág. 53. doi: http://dx.doi.org/10.16925/ di.v17i22.1242

\section{Resumen}

Tema y alcance: los conocimientos tradicionales son saberes y experiencias que se transmiten entre generaciones o resultan de los procesos de creación y experimentación. La variedad de estos conocimientos remarcan la complejidad en torno a su reconocimiento legal. Características: en este orden, los conocimientos tradicionales del terreno agrícola constituyen bienes inmateriales de preciado valor. Son, sin duda alguna, la solución necesaria y perentoria ante la escasez o la ausencia de recursos. Asimismo, se relacionan con otras categorías tales como sostenibilidad ambiental y desarrollo local, elementos que refuerzan su importancia y valía en los tiempos modernos. Conclusiones: el epicentro del presente artículo es el análisis de los conocimientos tradicionales agrícolas. En este sentido, se caracteriza la institución en función de su delimitación conceptual y naturaleza jurídica. Con igual atención, se desarrolla una valoración del régimen actual de protección en el marco de organismos e instrumentos internacionales.

Palabras clave: conocimientos tradicionales, derecho de autor, prácticas locales, propiedad industrial, propiedad intelectual. 


\title{
Intellectual Properties of a Sui Generis Nature: Traditional Knowledge of the Agricultural Sector. International Protection
}

\begin{abstract}
Topic and scope: Traditional knowledge consists of wisdom and experiences transmitted between generations, or which stem from processes of creation and experimentation. The variety of this knowledge is indicative of the complexity involved in its legal recognition. Characteristics: At this level, traditional knowledge of agriculture constitutes precious immaterial goods. They are undoubtedly the necessary and imperative solution for scarcity or lack of resources. They are also related to other categories such as environmental sustainability and global development, elements that increase in importance and value in modern times. Conclusions: The epicenter of this article is the analysis of traditional agricultural knowledge. In this regard, the institution is characterized as a function of its conceptual definition and legal nature. With equal emphasis, the current system for protection in the framework of international bodies and instruments is evaluated.
\end{abstract}

Keywords: traditional knowledge, copyright, local practices, industrial property, intellectual property.

\section{Bens intelectuais de natureza sui generis: os conhecimentos tradicionais do setor agrícola. Proteção internacional}

\section{Resumo}

Tema e alcance: os conhecimentos tradicionais são saberes e experiências que se transmitem entre gerações ou resultam dos processos de criação e de experimentação. A variedade desses conhecimentos reafirma a complexidade em torno de seu reconhecimento legal. Características: nesse sentido, os conhecimentos tradicionais do terreno agrícola constituem bens imateriais de valor estimado. Estes são, sem dúvida alguma, a solução necessária e urgente diante da escassez ou da ausência de recursos. Igualmente, relacionam-se com outras categorias, tais como sustentabilidade ambiental e desenvolvimento local, elementos que reforçam sua importância e valia nos tempos modernos. Conclusões: o epicentro do presente artigo é a análise dos conhecimentos tradicionais agrícolas. Nesse sentido, caracteriza-se a instituição em função de sua delimitação conceitual e natureza jurídica. Com igual atenção, desenvolve-se uma valorização do regime atual de proteção no âmbito de organismos e instrumentos internacionais.

Palavras-chave: conhecimentos tradicionais, direito autorais, práticas locais, propriedade industrial, propriedade intelectual. 


\section{INTRODUCCIÓN}

El Derecho como ciencia engloba un conjunto de ramas entre las que se encuentra la propiedad intelectual, ${ }^{1}$ cuyo objeto son las creaciones intelectuales y la represión de la competencia desleal. ${ }^{2}$ Se trata de una propiedad diferente, ya que sobre los bienes que ella protege se destaca la posesión total y simultánea del bien por varias personas. En relación con lo anterior, a fin de asegurar el disfrute exclusivo por parte de los titulares, es necesario prohibir a la colectividad el uso o explotación comercial del bien por parte del ordenamiento jurídico. ${ }^{3}$

Existen en el marco de esta rama del Derecho creaciones de diversa índole. Por un lado, las relativas a las creaciones artísticas, literarias y científicas; y por otro, las creaciones relacionadas con el desarrollo tecnológico y el funcionamiento del mercado. No obstante, existe un pequeño grupo dentro de este universo, el cual resulta de difícil ubicación o que puede ser situado en ambos terrenos: tal es el caso de los conocimientos tradicionales, cuando se dan los supuestos para ello.

Entre los estudiosos del tema, es posible encontrar autores como Caillaux Zazzali y Ruiz Muller, quienes consideran artificial la división entre cultura popular tradicional y conocimientos tradicionales asociados a la diversidad y sus componentes, debido a la existencia de zonas difusas. ${ }^{4}$

La denominación puede variar según el área, la esfera política y los instrumentos a los que se refiere.
Esta variedad responde a la importancia que presenta la institución para los diferentes ámbitos, entre los que es posible encontrar:

\begin{abstract}
"Innovaciones, prácticas y conocimientos tradicionales" en el contexto de la conservación y la utilización equitativa de los recursos biológicos; "patrimonio de los pueblos indígenas" y "derechos del patrimonio indígena"; "conocimientos médicos tradicionales" en el contexto de la política sanitaria; "expresiones del folclore" en el contexto de la protección del Derecho de Autor; "folclore" o "cultura tradicional y popular" en el contexto de la salvaguardia de la cultura tradicional; "patrimonio cultural inmaterial"; "propiedad intelectual indígena" y "propiedad intelectual y cultural indígena"; "conocimientos ecológicos tradicionales"; y "tecnología, conocimientos, habilidades y prácticas tradicionales y locales".
\end{abstract}

En el contexto internacional, los conocimientos tradicionales se enfrentan a un grupo no despreciable de problemáticas, entre las que se cuentan: ${ }^{6}$

1. Las apropiaciones indebidas. Sus manifestaciones se reflejan en la industria farmacéutica, cosmética y cultural ${ }^{7}$ (el patentamiento de formas vivas ${ }^{8}$ es muestra de ello). Las grandes empresas se apropian de los conocimientos y recursos de las comunidades con el fin de convertirlos en patentes sin el debido consentimiento y sin ofrecer participación de los beneficios derivados.

\footnotetext{
1. La propiedad intelectual abarca un amplio sector de creaciones intelectuales referidas a obras de arte, fijaciones de fonogramas, interpretaciones, ejecuciones y emisiones de radiodifusión, soluciones técnicas, variedades vegetales, signos que distinguen productos, servicios, establecimientos o empresarios, así como la represión de la competencia desleal. En torno a esta denominación, existen algunas objeciones ya que es asociada a criterios económicos y no técnicos, además engloba instituciones sobre las que no existe tal propiedad, como es el caso de la represión de la competencia desleal o los secretos empresariales.

2. En este caso constituye una institución y no una modalidad de la propiedad industrial, en tanto no otorga derechos exclusivos sino que constituye un segundo muro de contención al ofrecer una protección secundaria a las modalidades, ya sea por ausencia de legislación especial o por insuficiencia de la misma. Véase Dánice de la C. Vázquez D’Alvaré. La competencia desleal en el mercado cubano. Tesis de Doctorado en Ciencias Jurídicas. Universidad de La Habana. (2004). Pág. 12.

3. Véase Delia Lipszyc. Derecho de Autor y Derechos conexos. Tomo I. Editorial Félix Varela. (2001). Pág. 38.

4. Véase Jorge Caillaux Zazzali y Manuel Ruiz Muller. La protección jurídica de los conocimientos tradicionales y sus desafíos. ANUARIO Andino de Derechos Intelectuales 1. 2004. Pág. 3.
}

\footnotetext{
5. Existen otros términos también utilizados, tales como, "Conocimientos tradicionales, Conocimientos indígenas, Conocimientos comunitarios, Conocimientos ecológicos tradicionales, Conocimientos locales, Conocimientos medioambientales tradicionales, Tradición aborigen, Patrimonio cultural, Folclore, Expresiones del folclore, Patrimonio cultural, Medicina tradicional, Propiedad cultural, (Derechos) del patrimonio indígena, (Derechos) de la propiedad intelectual y cultural indígena, Propiedad intelectual indígena, Derechos del patrimonio consuetudinario, Conocimientos, innovaciones y prácticas tradicionales, Cultura popular, Componente intangible". Véase OMPI. Documento Wipo/Grtkf/IC/3/9. (2002). Pág. 13. Disponible en www.wipo.int; y anexo N. ${ }^{\circ}$ 1. Pág. 20.

6. Véase Martin Khor. El SAQueo del conocimiento. Propiedad INTELECTUAL, BIODIVERSIDAD, TECNOLOGÍA Y DESARROLLO SOSTENible. Icaria Editorial. (2003). Pág. 18.

7. Véase Bertha Luz Alvarado Castro. Rescate del Conocimiento tradicional. Desde la PERSPeCtiva de la NUEVA Legislación Forestal en Perú. Ed. Dirección General Forestal y de Fauna Silvestre. Ministerio de Agricultura (s/a). Pág. 2.

8. En este sentido, pueden ser consultados los casos del algodón Bt (Bacilusthuringiensis), papa Bt, maíz Bt y quinoa boliviana Apelawa. Cf. Martin Khor, supra, nota 6. Págs. 25-26.
} 
2. La invasión de las formas de vida modernas. Provoca la sustitución de la tradición por la modernización, las técnicas ancestrales de abonar la tierra por los agroquímicos y la música tribal por la comercial.

3. Las migraciones. Constituyen movimientos poblacionales con incidencia en diferentes espacios geográficos (entiéndase estos como el lugar de origen y el lugar de destino). ${ }^{9}$ Sus impactos se manifiestan en el orden económico y se extienden a las relaciones internacionales, a la vez que conducen a una mayor diversidad étnica y cultural, transforman las identidades y desdibujan las fronteras tradicionales. Constituye un sello del encuentro entre estas culturas la conflictividad, en tanto se produce una negación del emigrante, un rechazo a su cultura y sus estilos de vida. ${ }^{10}$ De otra parte, el traslado de personas del campo a la ciudad hace que se debilite la base de recursos humanos.

4. Las presiones sociales y medioambientales. Ante situaciones de pobreza o inclemencias ambientales, los pobladores se ven obligados a abandonar sus tradiciones para dedicarse a otras labores más productivas o asentarse en otros territorios con mejores condiciones climáticas.

5. La falta de respeto hacia la contribución de estas comunidades y el desinterés por su preservación. $\mathrm{Al}$ ser considerados arcaicos en algunos casos, hace que se relegue su uso, valor y preservación.

6. La pérdida del idioma que da voz a una tradición de conocimiento. ${ }^{11}$

7. La imposibilidad de participación equitativa en los beneficios. $^{12}$

Dichas problemáticas resultarían menos significativas si existieran los mecanismos jurídicos y

9. Véase Antonio Aja Díaz. Desigualdades y migraciones internacionales: una serpiente que se muerde la cola. Revista Temas 45. Enero-marzo de 2006. Págs. 55- 66.

10. Esto produce una reacción que puede ir en dos sentidos: el desentendimiento con sus orígenes o la persistente defensa de su identidad. El primero de ellos atenta contra la preservación de las tradiciones, ya que ante la inexistencia de protección en el país de origen y la renuncia forzada en el país de destino, se produce la pérdida total e irreparable de esos conocimientos tradicionales.

11. De las 6000 lenguas existentes en el planeta, en promedio muere una cada dos semanas. Véase Lilian Álvarez Navarrete. Derecho DE ¿AUTOR? EL DEBATE DE HOY. Ciencias Sociales. (2006). Pág. 50.

12. En el marco del cig se refleja como un objetivo, el cual propugna el derecho de las comunidades a participar de los beneficios que se derivan de la utilización de los conocimientos tradicionales, cuestión de mayor incidencia en aquellos casos de conocimientos tradicionales asociados a recursos genéticos. En relación con el valor de este postulado véase Jorge Caillaux Zazzali y Manuel Ruiz Muller, supra, nota 4. Págs. 5, 8, 13 y 14 políticos idóneos para una adecuada protección de los conocimientos.

No escapan de esta entramada situación los conocimientos tradicionales del sector agrícola, los cuales dada su importancia y relación con categorías tales como desarrollo sostenible y soberanía alimentaria, requieren un apartado especial. De ahí que el objetivo principal del presente artículo sea identificar posibles ámbitos de protección para estos conocimientos en los diferentes instrumentos jurídicos y los debates internacionales que guardan relación con el tema.

\section{DesarRollo}

\section{A. Delimitación conceptual de los conocimientos tradicionales}

Los conocimientos tradicionales son saberes individuales ${ }^{13}$ o colectivos sobre el entorno natural y social, sin dejar al margen los constantes cambios sociales. Este proceso de socialización se convierte en una relación de acción e interacción, cuyos resultados se reflejan en la vida diaria.

En el ámbito jurídico, existen instrumentos que se refieren a la definición de los conocimientos tradicionales de forma ejemplificativa, de manera que puedan quedar comprendidos aquellos que no están referidos en la norma..$^{14}$ Otros, por su parte, se refieren a ellos a partir de la descripción de determinadas características ${ }^{15}$ tal como es el caso de la Ley

13. En este sentido, cabe aclarar que no constituye un debate zanjado el reconocimiento del carácter individual de los conocimientos tradicionales, pues en la mayoría de los casos se consideran colectivos - criterio que no comparte la autora-, en razón a la existencia de individuos aislados que también poseen determinados conocimientos surgidos en contextos locales.

14. La definición ofrecida por la Organización Mundial de Propiedad Intelectual (OMPI) engloba las creaciones artísticas y no artísticas: "Las obras literarias, artísticas o científicas basadas en las tradiciones, las ejecuciones, las invenciones, los descubrimientos científicos, los diseños, las marcas, los nombres y los símbolos, la información no divulgada y todas aquellas otras innovaciones y creaciones (basadas en la tradición), y que resultan de la actividad intelectual en los campos industrial, científico, literario y artístico. Véase ompi. Panorama de las cuestiones globales de la Propiedad Intelectual: La PRotección del Folclore, LOS CONOCIMIENTOS TRADICIONALES Y LA BIODIVERSIDAD. (2000). Pág. 4. Disponible en www.wipo.int.

15. La referencia puede ser subjetiva, es decir, del ámbito en que surgen conocimientos tradicionales de comunidades locales o indígenas. También puede ser objetiva, dirigida al conocimiento tradicional per se: por ejemplo cuando se alude a los conocimientos 
de Protección del Patrimonio de los Aborígenes y los Isleños del Estrecho de Torres de Australia (1984) ${ }_{1}^{16}$ en la cual se hace alusión al contexto en que estos conocimientos tradicionales se desenvuelven al emplear el concepto de tradición aborigen. Por su parte la Ley 7788 de Biodiversidad de Costa Rica (23 de abril de 1998), en su artículo 7.2, establece lo que se entiende por biodiversidad, delimitando de esta forma el objeto de protección, esto es, aquellos conocimientos tradicionales asociados a los recursos bioquímicos y genéticos. En igual sentido, es posible citar la Decisión 391 relativa al Régimen Común sobre Acceso a los Recursos Genéticos (Comunidad Andina). ${ }^{17}$ Por su parte, la Decisión 486 del Patrimonio Biológico y Genético y de los Conocimientos Tradicionales de la Comunidad Andina de Naciones ${ }^{18}$ alude a los

tradicionales biológicos, los asociados a recursos genéticos o aquellos que añaden un valor al producto al que son incorporados. En otro sentido, se utiliza también como referencia el hecho de encontrarse en dominio público, lo que resulta objetable ya que no resulta así en todos los casos, particularmente aquellos que pueden ser objeto de protección a través de los secretos empresariales.

16. En el artículo $3 c$ de esta ley se lee: "Tradición aborigen se refiere al cuerpo de tradiciones, prácticas, costumbres y creencias de los aborígenes en general o de una comunidad particular o grupo de aborígenes, e incluye cualquier tradición, práctica, costumbre o creencia relacionada con personas, lugares, objetos o relaciones particulares". Véase Ley de Protección del Patrimonio de los Aborígenes y los Isleños del Estrecho de Torres de Australia. 1984. Disponible en www.austlii.edu.au/au/legis/cth/ consol_act/aatsihpa1984549.txt.

17. Componente intangible: todo conocimiento, innovación o práctica individual o colectiva, con valor real o potencial, asociado al recurso genético, o sus productos derivados o al recurso biológico que los contiene, protegido o no por regímenes de propiedad intelectual. Véase Decisión 391 relativa al Régimen Común sobre Acceso a los Recursos Genéticos (Comunidad Andina). Disponible en www.comunidadandina.org/desarrollo/dct4.PDF.

18. En el artículo 3 se lee: "Los países miembros asegurarán que la protección conferida a los elementos de la propiedad industrial se concederá salvaguardando y respetando su patrimonio biológico y genético, así como los conocimientos tradicionales de sus comunidades indígenas, afroamericanas o locales. En tal virtud, la concesión de patentes que versen sobre invenciones desarrolladas a partir de material obtenido de dicho patrimonio o dichos conocimientos estará supeditada a que ese material haya sido adquirido de conformidad con el ordenamiento jurídico internacional, comunitario y nacional. Los Países Miembros reconocen el derecho y la facultad para decidir de las comunidades indígenas, afroamericanas o locales, sobre sus conocimientos colectivos". De igual forma, en el artículo 136.g: "Consistan en el nombre de las comunidades indígenas, afroamericanas o locales, o las denominaciones, las palabras, letras, caracteres o signos utilizados para distinguir sus productos, servicios o la forma de procesarlos, o que constituyan la expresión de su cultura o práctica, salvo que la solicitud sea presentada por la propia comunidad o con su consentimiento expreso." Véase Decisión 486 de 2000. [Comunidad Andina]. Que establece el Régimen Común sobre Propiedad Industrial. Septiembre 14 de 2000 conocimientos de las comunidades locales y también al tipo de conocimientos tradicionales, a saber, aquellos relacionados con los recursos biológicos.

\section{Pautas para una definición de conocimientos tradicionales agrícolas}

El elemento consuetudinario cumple un rol fundamental. Más allá de incidir en una definición adecuada, su importancia radica también en la forma de protección. Asimismo, los conocimientos tradicionales confieren determinada identidad a las comunidades, aspecto también valorable para una definición.

Existen sistemas de conocimientos tradicionales que se encuentran codificados, ${ }^{19}$ pero no constituyen una generalidad. Una situación similar se manifiesta en relación con la transmisión de generación en generación y la producción de forma colectiva, elementos claves al momento de ofrecer una definición, pues de lo contrario quedarían fuera del ámbito de protección algunas tipologías.

La definición debe ser lo suficientemente abarcadora sin enmarcarse en categorías de conocimientos tradicionales o formas de protección. No obstante, existen elementos que no deben ser perdidos de vista, tales como ${ }^{20}$ el contexto en que se desarrollan, preservan y transmiten, su relación con la comunidad de la que provienen, la obligación de preservación de las comunidades y el rechazo a la apropiación indebida, el amplio ámbito de conocimientos tradicionales existentes y la identificación como tal por parte de los poseedores.

A propósito del tema, diversos autores han referido sus consideraciones, algunas de las cuales se citan a continuación.

19. La TKDL es el resultado de la colaboración y esfuerzo de varias instituciones indias relacionadas con la medicina, la ciencia y la tecnología, especialistas en propiedad industrial. Para la conformación de esta biblioteca virtual, se hizo una catalogación de los conocimientos tradicionales a disposición del público en forma de literatura existente relacionada con la medicina Ayurveda, Unani, Siddha y Yoga, la cual se encuentra también disponible en formato digital en cinco idiomas internacionales (inglés, alemán, francés, japonés y español). Para mayor información, véase OMPI. DOCUMENTO PR/2011/682. (2011). Disponible en www.wipo.int. La base de datos de patentes sobre medicina tradicional china contiene más de 12.124 registros indizados de información en materia de patentes sobre medicina tradicional. Fue creada por la Oficina Estatal de Propiedad Intelectual de la República Popular China. Véase OMPI. DOCUMENTO OMPI/GRTKF/IC/7/7. (2004). Disponible en www. wipo.int. Pág. 5.

20. Véase OMPI. Documento WIPo/GRTKF/IC/3/9, supra, nota 5 . Pág. 16. 
Para John Mugabe:

Los conocimientos tradicionales corresponden al conjunto de todos los conocimientos y prácticas, explícitos o implícitos, que se utilizan en la gestión de las facetas socioeconómicas y ecológicas de la vida. Estos conocimientos se basan en las experiencias pasadas y en la observación y suelen ser propiedad colectiva de una sociedad. ${ }^{21}$

Por su parte, George Hobson propone que "los conocimientos tradicionales son los conocimientos y las interpretaciones acumulados sobre el lugar que ocupan los seres humanos en el mundo, tanto en el sentido ecológico como espiritual". ${ }^{22} \mathrm{Y}$ de acuerdo con Gustavo Capdevilla, "los conocimientos tradicionales se definen como 'los conocimientos, innovaciones y prácticas de las comunidades locales e indígenas que encarnan estilos de vida tradicionales', así como las 'tecnologías locales e indígenas"”. ${ }^{23}$

La Secretaría de Estado del Medio Ambiente de Canadá propone que "los conocimientos ecológicos tradicionales se definen como los conocimientos adquiridos por pueblos locales e indígenas a través de generaciones de contacto directo con el medio ambiente" 24 .

La Ley N. ${ }^{\circ} 27811$ de Perú que establece un Régimen Especial de Protección de los Conocimientos Colectivos de los Pueblos Indígenas Asociados a la Diversidad Biológica (2002), por su parte plantea el conocimiento colectivo "como el conocimiento acumulado y transgeneracional desarrollado por los pueblos y comunidades indígenas respecto a las propiedades, usos y características de la diversidad biológica". ${ }^{25}$

21. Véase John Mugabe. LA PROTECCIÓN DE LA PRopiedAd INTELECTUAL Y LOS CONOCIMIENTOS TRADICIONALES. UN ANÁLISIS DE LA ORIENTACIÓN DE LAS NORMAS DE POLÍTICA INTERNACIONAL. (1998). Disponible en http://www.acts.or.ke.

22. Véase George Hobson. Traditional Knowledge is Science. Disponible en http://www.carc.org/ pubs/v20nol/science.htm.

23. Véase Gustavo Capdevila. Indigenous PeOples DefEnd TRADITIONAL KNOWLEDgE. InterPress Third World News Agency (2000). Disponible en www.forest.org/archive/general/indefkno.htm.

24. Véase OMPI. Documento WIPo/GRTKF/IC/3/9, supra, nota 5.

Pág. 8 .

25. Ley N. ${ }^{\circ} 27811$ de 2002. Establece un Régimen Especial de Protección de los Conocimientos Colectivos de los Pueblos Indígenas Asociados a la Diversidad Biológica. (Julio 24 de 2002). Para conocer sobre el proceso de aprobación y cuestiones asociadas a esta norma, véase Manuel Ruiz Muller. LA PROTECCIÓN JURÍ DICA DE LOS CONOCIMIENTOS TRADICIONALES: ALGUNOS AVANCES POLÍTICOS Y NORMATIVOS EN AMÉRICA LATINA. UICN, BMZ, SPDA (2006). Pág. 128.
Elementos comunes de estas definiciones son la pertenencia a una comunidad específica (bien sea local o indígena), y la transmisión entre generaciones. En correspondencia con estos elementos y a criterio de la autora, los conocimientos tradicionales agrícolas son el conjunto de saberes y experiencias agrícolas individuales o colectivas que se transmiten en el marco de una comunidad, localidad o grupo social, y los cuales llevan en sí mismos la impronta temporal y espacial de cada momento ya sea en el campo artístico, técnico, científico o agrícola, por sólo citar algunos campos.

\section{B. Naturaleza jurídica de los conocimientos tradicionales. Particularidades en el ámbito agrícola}

La naturaleza jurídica es la calificación que corresponde a las relaciones o instituciones jurídicas, conforme a los conceptos utilizados por determinado sistema normativo. ${ }^{26}$ En este sentido, surgen los siguientes interrogantes: ¡cómo calificar los conocimientos tradicionales? ¿Cómo calificar ese conjunto de experiencias y saberes?

Tobón Franco sostiene, al referirse a los conocimientos tradicionales, que se trata de una "naturaleza sagrada y no racional", ${ }^{27}$ y lo hace atendiendo al criterio distintivo de los conocimientos tradicionales en relación con las demás instituciones de la propiedad intelectual.

En otro sentido, el artículo 10 de la Ley N. ${ }^{\circ} 2711$ de Perú dispone que se trata de una naturaleza colectiva, entendida esta como la pertenencia de dichos conocimientos tradicionales a determinadas colectividades, con independencia del reconocimiento individual a los creadores - cuando así fuera- hacia lo interno de la comunidad. ${ }^{28}$ En este punto, la autora coincide con el carácter colectivo de los conocimientos tradicionales cuando resulte imposible identificar de forma individual al creador, no así en los supuestos de creadores individuales, aun cuando dicha titularidad sea reconocida hacia lo interno de la comunidad.

Esta situación responde puntualmente a escenarios en los que el ejercicio individual de los derechos pudiera resultar más complicado que el ejercicio de forma colectiva, o desde otra perspectiva, las disposiciones consuetudinarias conciben el ejercicio de los

\footnotetext{
26. Véase Manuel Ossorio. DICCIONARIO DE CIENCIAS JURÍDICAS POLÍTICAS Y SOCIALES. Datascan. (s/a). Pág. 615.

27. Natalia Tobón Franco. Un enfoque diferente para la protección de los conocimientos tradicionales de los pueblos indígenas. Revista Estudios Socio-jurídicos 1. (Enero-junio del 2007). Pág. 1. 28. Véase Manuel Ruiz Muller, supra, nota 26. Pág. 131.
} 
derechos a nombre de la colectividad por encima del ejercicio individual para estos asuntos. Dada la diversidad de criterios que a propósito del tema pueden derivarse, la autora sostiene la posición de no delegar la naturaleza jurídica de los conocimientos tradicionales en su carácter colectivo, ya que no en todos los sistemas jurídicos son reconocidos de esa forma.

Los conocimientos tradicionales tienen una particularidad que no poseen las instituciones de la propiedad intelectual: se trata de su naturaleza diversa y compleja que responde a las disímiles tipologías que abarca y, en consecuencia, un ámbito jurídico que no escapa de esta complejidad. En el ámbito académico, la naturaleza jurídica de los conocimientos tradicionales ha sido abordada con parquedad, limitándose el análisis a su ubicación o no en el terreno de la propiedad intelectual. Por tanto, es preciso analizar los elementos que distinguen a los bienes agrupados en esta rama del Derecho, de manera que sea posible determinar si los conocimientos tradicionales son parte o no de esta.

En relación con el carácter inmaterial de las instituciones que ocupan el objeto de estudio de la propiedad intelectual, se han planteado algunos elementos a raíz de la existencia de diferentes áreas, tales como propiedad industrial, Derecho de autor y derechos conexos. Baylos Corroza al abordar el tema, expone cómo el hecho de tratar de conjunto los derechos que se refieren a bienes inmateriales no constituye un antagonismo. ${ }^{29}$ Por su parte, Lipszyc observa esta conjunción desde lo doctrinal y lo docente-metodológico como algo tradicional, ya que se agrupan derechos de distinta índole que tienen por objeto bienes inmateriales..$^{30} \mathrm{El}$ elemento común es que se trata de derechos sobre bienes inmateriales que presentan grandes diferencias entre sí. Dicho carácter inmaterial se identifica con un grupo de particularidades ${ }^{31}$, entre las que se cuentan las siguientes.

1. No son bienes susceptibles de un disfrute inmediato, necesitan plasmarse en algo corpóreo

Dentro de la gama de conocimientos tradicionales existentes pueden observarse situaciones en las que resulta fácilmente observable este requisito, como

29. Véase Hermenegildo Baylos Corroza. Tratado de Derecho Industrial. Civitas. (1978). Pág. 50.

30. Véase Delia Lipszyc. Derecho de autor y derechos Conexos. Tomo I. Editorial Félix Varela. (2001). Pág. 12.

31. Véase Andryth Aguilar Villán. Los SECretos empresaria les como parte de la Propiedad Industrial. Reflexiones en el caso cubano. Tesis de Doctorado en Ciencias Jurídicas. Universidad de La Habana. (2008). Pág. 30. en el caso de la medicina tradicional. Sin embargo, si bien los métodos de cultivo o uso de abono natural no requieren estar plasmados en un soporte para ser empleados por los agricultores, esto no impide que tengan un carácter inmaterial.

En principio son ilimitadamente repetibles y varias personas pueden usarlos y disfrutarlos simultáneamente, sin impedir que continúen produciendo beneficios para su titular. En este aspecto sólo hay que resaltar que en sede de conocimientos tradicionales no siempre existe titularidad, ya que no hay entidad administrativa que se pronuncie en torno a la concesión de derechos, bien sea porque no cumplen los requisitos legales de protección a través de los mecanismos de propiedad intelectual, o bien porque no entran en su marco. Es por esto que resulta pertinente el uso del término posesión ${ }^{32}$ y no titularidad $^{33}$ desde el punto de vista de la propiedad intelectual, aunque puede existir titularidad en el marco del derecho consuetudinario por el que se rigen las comunidades y existe titularidad en relación con los derechos que se derivan de ese estado posesorio.

2. Usualmente, generan derechos temporales, determinados por la ley o por una situación de hecho

En este sentido, los conocimientos tradicionales implican una posesión atemporal al no estar sujetos a una duración limitada por la norma. Su vigencia está asociada al mantenimiento de la tradición y de la existencia física de sus poseedores; en otras palabras, puede decirse que los conocimientos tradicionales generan una posesión atemporal que puede ser determinada por situaciones de hecho tales como la pérdida de la tradición o la inexistencia de sus poseedores. Cuestión distinta se manifiesta en aquellos supuestos de conocimientos tradicionales que se materializan en obras, invenciones, diseños industriales, modelos de utilidad y creaciones cuya

32. La posesión es un estado de hecho, según el Código Civil sobre bienes tangibles. No obstante, otros sistemas aceptan la posesión sobre bienes intangibles. Véase Orlando Rivero Valdés. TeMAS DE Derechos Reales. Editorial Félix Varela. (2007). Pág. 94.

33. El derecho de propiedad no es, a fin de cuentas, más que una relación jurídica en la que figura como titular el propietario; y como sujetos pasivos obligados a reconocer sus prerrogativas el resto de los ciudadanos, a quienes mediante un poderoso aparato de coacción y represión se les mantiene imposibilitados de interferir con el disfrute exclusivo del titular del privilegio. Sin la intervención estatal que garantice el ejercicio del derecho de propiedad sería letra muerta este supuesto derecho individual. Véase Vicente Rapa Álvarez. Propiedad y otros derechos Sobre bienes. Facultad de Derecho, Universidad de La Habana. (1990). Pág. 21. 
protección sí está sujeta a un plazo de duración determinado.

\section{Bienes económicos con valor patrimonial}

Los poseedores de conocimientos tradicionales no siempre les atribuyen valores de esta índole, se trata más bien de valores espirituales y culturales. El valor patrimonial puede verse relacionado con aquellos conocimientos tradicionales que se materializan en creaciones protegibles por la propiedad intelectual.

A partir de este análisis, es necesario destacar que los conocimientos tradicionales, aun cuando presentan características afines con los bienes inmateriales, tienen una singularidad que se impone. ${ }^{34}$ De allí que el sistema de protección que propugna la propiedad intelectual presente limitaciones - como se verá más adelante- en relación con determinadas tipologías, lo cual ha dado lugar al nacimiento de sistemas sui generis de protección.

Los conocimientos tradicionales protegibles por el derecho de patentes, obras literarias, científicas o artísticas, secretos empresariales o signos distintivos, tienen una naturaleza intangible que se enmarca en los elementos antes relacionados o en la mayoría de ellos. Sin embargo, en lo que respecta a los saberes y experiencias agrícolas, por ejemplo, el análisis ha de ir en otra dirección. En primer lugar, se trata de creaciones del intelecto humano, intangibles e incorpóreas (en lo atinente a la plasmación en algo corpóreo habría que describir qué se entiende por tal, ya que no se manifiesta el mismo régimen que en instituciones de la propiedad intelectual). De esta manera, ¿mezclar cultivos, utilizar las heces de animales para abonar la tierra precisan constituirse en formas corpóreas para su disfrute? En este sentido, la respuesta no es afirmativa, ya que los conocimientos tradicionales agrícolas son bienes inmateriales cuyo disfrute no depende de corporeidad alguna.

En relación con el disfrute ilimitado y simultáneo, es aplicable a los conocimientos del sector agrícola. Sin embargo, no resulta así en relación con la generación de derechos, ya que se trata generalmente de saberes que pertenecen al dominio público y son compartidos por un número indeterminado de personas, aunque no siempre tiene que ser así. Por último, el valor patrimonial - de existir - estará en dependencia de las

\footnotetext{
34. Esta situación no es exclusiva de los conocimientos tradicionales. Los secretos empresariales y la represión de la competencia desleal presentan análisis similares. Véase Andryth Aguilar Villán, supra, nota 31. Págs. 30-31 y Dánice de la C. Vázquez D’Alvaré, supra, nota 2. Pág. 25.
}

características del producto resultante de la aplicación de esos conocimientos tradicionales.

Como nota conclusiva, urge puntualizar que los conocimientos tradicionales tienen una naturaleza sui generis que les impide ajustarse mutatis mutandis al contenido de la propiedad intelectual. No obstante, comparten un grupo de elementos a valorar en relación con el carácter inmaterial.

\section{Expresión normativa de la protección de los conocimientos tradicionales en el contexto internacional. Posibles interpretaciones en función del reconocimiento de los conocimientos tradicionales del sector agrícola}

Antes de la comercialización de bienes intangibles, es preciso prever un sistema de protección coherente en correspondencia con su naturaleza y con los intereses de sus poseedores a fin de evitar pérdidas irreparables.

Entre los elementos que sustentan la necesidad de protección está precisamente la conservación de la biodiversidad y el mantenimiento de los métodos de producción agrícolas sustentables, ya que resultan innegables las propiedades que tienen los conocimientos tradicionales para la medicina, la cosmetología, la alimentación y las especies y variedades que utilizan las comunidades. ${ }^{35}$

El uso de leyes, valores y principios de propiedad intelectual, en el marco de los conocimientos tradicionales, tiene por fin frenar los usos no autorizados o inadecuados a través de dos formas: la protección positiva y la preventiva. Mediante la protección positiva se otorgan derechos exclusivos, los cuales resultan de gran utilidad al impedir el acceso ilegítimo o el uso con ánimo de lucro por parte de terceros sin una participación equitativa en los beneficios. Asimismo, mediante dicha protección la comunidad de origen puede explotar activamente los conocimientos tradicionales o permitir el acceso bajo determinadas condiciones. De otra parte, mediante la protección preventiva no se otorgan derechos exclusivos pero se impide su adquisición por terceros, tal es el caso de la catalogación de conocimientos tradicionales para ser incorporados en los exámenes de patentes. ${ }^{36}$

35. Las comunidades del Altiplano Andino han contribuido a conservar un gran número de variedades de papa no conocidas hasta hace poco. Véase OMPI. DOcUMENTO OMPI/GRTKF/IC/1/5. (2001). Pág. 3. Disponible en www.wipo.int.

36. La protección en el sentido de la propiedad intelectual es distinta de la "conservación" y la "salvaguardia", que tienen que ver con la identificación, catalogación, transmisión, revitalización 
Las medidas de preservación se dirigen a mantener el estado de objetos físicos, es decir, la conservación de registro de conocimientos tradicionales, la fijación en algún soporte — cuando no se ha hecho-, el uso generalizado por parte de la comunidad ante la posible pérdida, así como la promoción de normas que tributen a todo lo anterior.

En cualquier caso, la protección implica un nivel de control, del cual puede encargarse la comunidad o un ente destinado al efecto.

En el plano internacional existen un conjunto de normas que si bien no ofrecen atención al fenómeno en toda su extensión, brindan algún tipo de protección.

\section{Declaración Universal de Derechos Humanos}

En su artículo $27,{ }^{37}$ establece que todos los pueblos tienen derecho a la creación y a la participación de sus creaciones, así como el derecho a protegerlas. En el tema que ocupa el centro de esta investigación, se trata de creaciones intelectuales, por tanto, las comunidades poseedoras detentan en sus manos el derecho a protegerlas según sus propios mecanismos, así como a participar de los beneficios económicos y morales que de ellas se deriven. Aspecto que, a criterio de la autora, ha de ser positivizado en las normas internas de los Estados a fin de delimitar porcentajes

y promoción del patrimonio cultural. El objetivo en ese caso es velar por que los СС.тт. y las ЕCT no desaparezcan, se mantengan y se promuevan.

La "protección", la "conservación" y la "salvaguardia" no se excluyen mutuamente. Aunque tienen objetivos distintos, pueden respaldarse la una a la otra al aplicarse de manera conjunta. Por ejemplo, por medio de la catalogación y la compilación de inventarios. Sin embargo, esas formas distintas de protección también pueden entrar en conflicto. Los esfuerzos de conservación mediante la catalogación de CC.TT. о ECT, en particular en forma electrónica (digitalizada), pueden hacer más accesibles los conocimientos y las expresiones y volverlos más vulnerables a utilizaciones no autorizadas por sus poseedores y, de ese modo, menoscabar los esfuerzos de protección mediante derechos de P.I. Por lo tanto, resulta aconsejable establecer políticas para la gestión estratégica de la P.I. durante la labor de registro, digitalización y difusión de Cс.тT. y ECT. Véase http://www.wipo.int/export/sites/www/tk/es/resources/ pdf/tk_brief3.pdf.

37. "1. Toda persona tiene derecho a tomar parte libremente en la vida cultural de la comunidad, a gozar de las artes y a participar en el progreso científico y en los beneficios que de él resulten. 2. Toda persona tiene derecho a la protección de los intereses morales y materiales que le correspondan por razón de las producciones científicas, literarias o artísticas de que sea autora." Véase U.N. Declaración Universal de Derechos Humanos. Artículo 27. (Diciembre 10 de 1948). Disponible en http://www.un.org/spanish/ aboutun/hrights.html. de participación y medidas correctivas ante posibles infracciones.

\section{Convenio sobre Diversidad Biológica (CBD)}

En el CBD existe un reconocimiento expreso de la figura objeto de estudio, así como de los derechos de las comunidades, especialmente el derecho a disfrutar de los beneficios derivados de su uso. El preámbulo es muestra de ello al reconocer:

La estrecha y tradicional dependencia de muchas comunidades locales y poblaciones indígenas que tienen sistemas de vida tradicionales basados en los recursos biológicos, y la conveniencia de compartir equitativamente los beneficios que se derivan de la utilización de los conocimientos tradicionales, las innovaciones y las prácticas pertinentes para la conservación de la diversidad biológica y la utilización sostenible de sus componentes. ${ }^{38}$

En correspondencia con la posición anterior se encuentra el artículo 8 , inciso $\mathrm{j},{ }^{39}$ el cual exhorta a los Estados a brindar protección a través del Derecho interno, que si bien constituye un paso de avance, no ofrece un derecho concreto a estas creaciones. No obstante, no se establecen pautas capaces de guiar a los Estados. Menos esperanzadora resulta la expresión "en la medida de lo posible" que sin duda crea un margen de actuación o no bastante amplio. En sentido contrario y como aspecto positivo de esta normativa, está el reconocimiento del artículo $10 . c^{40}$ que complementa lo anterior a partir de la distinción del papel de los poseedores de conocimientos tradicionales en la protección y su utilización, lo que da cabida a las normas consuetudinarias, incluso fuera del marco de los derechos de propiedad intelectual. En la misma

\footnotetext{
38. Véase https://www.cbd.int/doc/legal/cbd-es.pdf

39. “Artículo 8. Conservación in situ. Cada Parte Contratante, en la medida de lo posible y según proceda: j) Con arreglo a su legislación nacional, respetará, preservará y mantendrá los conocimientos, las innovaciones y las prácticas de las comunidades indígenas y locales que entrañen estilos tradicionales de vida pertinentes para la conservación y la utilización sostenible de la diversidad biológica y promoverá su aplicación más amplia, con la aprobación y la participación de quienes posean esos conocimientos, innovaciones y prácticas, y fomentará que los beneficios derivados de la utilización de esos conocimientos, innovaciones y prácticas se compartan equitativamente".

40. "Artículo 10. Utilización sostenible de los componentes de la diversidad biológica. Cada Parte Contratante, en la medida de lo posible y según proceda: c) Protegerá y alentará la utilización consuetudinaria de los recursos biológicos, de conformidad con las prácticas culturales tradicionales que sean compatibles."
} 
tesitura en el sentido del reconocimiento y respeto, el artículo 18.4 ofrece una amplia definición de tecnología y se incluyen específicamente aquellas de origen tradicional..$^{41}$

A juicio de la autora, este tratado reconoce que ha de existir protección a un grupo de conocimientos tradicionales: aquellos asociados a los recursos genéticos. Esto constituye un esfuerzo importante en el plano internacional por destacar la contribución de las comunidades indígenas y locales, pero no se ofrecen mecanismos concretos de protección.

\section{Las Directrices de Bonn}

En relación con el CDB, se encuentran las "Directrices de Bonn" sobre acceso a los recursos genéticos y participación justa y equitativa en los beneficios provenientes de su utilización, ${ }^{42}$ adoptadas por la Conferencia de las Partes en el CDB en el 2002, con el objetivo de orientar sobre la aplicación de las disposiciones previstas en los artículos 8.j, 10.c, 15, 16 y 19 del CDB relativos a la temática antes referida. En ellas se exhorta a las partes contratantes en el CDB a brindar protección preventiva a los recursos genéticos y conocimientos asociados, ya que promueven la adopción de medidas que revelen el origen de estos en las solicitudes de derechos de propiedad intelectual, así como la cooperación entre las partes contratantes a fin de tratar supuestos de violación de pacto de acceso y distribución de beneficios, sistemas de certificación para instituciones que cumplen las reglas sobre acceso y participación en los beneficios, y medidas que permitan frenar prácticas comerciales injustas.

En igual sintonía con el convenio que les da origen, sólo abarcan los conocimientos tradicionales relacionados con recursos genéticos y su carácter no vinculante hace que no impliquen un compromiso a asumir por los Estados (su función es orientadora).

41. "Artículo 18. Cooperación científica y técnica. 4. De conformidad con la legislación y las políticas nacionales, las Partes Contratantes fomentarán y desarrollarán métodos de cooperación para el desarrollo y utilización de tecnologías, incluidas las tecnologías autóctonas y tradicionales, para la consecución de los objetivos del presente Convenio. Con tal fin, las Partes Contratantes promoverán también la cooperación para la capacitación de personal y el intercambio de expertos."

42. Véase Apartado d) del párrafo 16 de las Directrices de Bonn. Estas directrices no tienen carácter vinculante y fueron adoptadas de forma unánime por 180 países, su objeto es favorecer el desarrollo de mecanismos y sistemas de acceso y participación donde se protejan los conocimientos tradicionales de las comunidades.
4. Protocolo de Nagoya sobre Acceso a los Recursos Genéticos y Participación Justa Equitativa en los Beneficios que se deriven de su Utilización al Convenio sobre Diversidad Biológica ${ }^{43}$

Su fin es impulsar el tercer objetivo del Convenio sobre la Diversidad Biológica, y dota a proveedores y usuarios de recursos genéticos de una mayor transparencia y seguridad jurídica. Incorpora dos aspectos importantes:

1. Un conjunto de obligaciones concretas a cumplir por los Estados en aras de garantizar el cumplimiento de lo estipulado, así como las condiciones de cooperación mutua acordadas.

2. Un conjunto de disposiciones relativas al acceso a los conocimientos tradicionales asociados a recursos genéticos de las comunidades, en aras de fortalecer la capacidad de beneficio de los poseedores.

3. Precisamente entre las cuestiones que no ofrecían suficiente claridad en el CDB se encontraba lo relativo a la participación en los beneficios, cuestión que queda resuelta con este nuevo tratado al ofrecer pautas generales de carácter vinculante a seguir por los Estados, a diferencia de las "Directrices de Bonn" que no tienen este carácter.

\section{Tratado Internacional sobre los Recursos}

Fitogenéticos para la Alimentación y la Agricultura (TIRFA)

El tirfa, o también identificado como el "Tratado de Semillas", se adoptó por parte de los Estados miembros de la FAO (Organización de las Naciones Unidas para la Alimentación y la Agricultura) en el año 2001 y entró en vigor en el 2004. En su artículo 9 se establece cómo "la conservación, la utilización, el intercambio, la venta de material de siembra y de propagación conservados en las fincas" es un derecho del agricultor, derecho que abarca un conjunto de conocimientos tradicionales, según se establece en el propio artículo. ${ }^{44}$ Según opinión de la autora, se reconoce

43. Véase Protocolo de Nagoya. (Octubre 29 de 2010). Disponible en www.cbd.int.

44. "Artículo 9.2 Las Partes Contratantes acuerdan que la responsabilidad de hacer realidad los Derechos del agricultor en lo que se refiere a los recursos fitogenéticos para la alimentación y la agricultura incumbe a los gobiernos nacionales. De acuerdo con sus necesidades y prioridades, cada Parte Contratante deberá, según proceda y con sujeción a su legislación nacional, adoptar las medidas pertinentes para proteger y promover los Derechos del agricultor, en particular: a) la protección de los conocimientos tradicionales de interés para los recursos fitogenéticos para la alimentación y la agricultura". Véase Protocolo de Nagoya, supra, nota 43. 
el conocimiento tradicional agrícola per se y su protección como un derecho, ${ }^{45} \mathrm{y}$ si bien no se establece en qué consiste esa protección, constituye un punto de partida para las normas internas.

\section{Declaración de Interlaken sobre los Recursos Zoogenéticos}

Con la "Declaración de Interlaken"46 se persigue el respeto y la preservación de los conocimientos tradicionales asociados a la cría y la producción de animales "como contribución a unos medios de vida sostenibles", lo que se encuentra en franca sintonía con el "Plan de Acción Mundial sobre los Recursos Zoogenéticos ${ }^{47}$, el cual tiene por objeto, entre otros,

Promover una repartición justa y equitativa de los beneficios derivados de la utilización de los recursos zoogenéticos para la alimentación y la agricultura, y reconocer la función del conocimiento tradicional, las innovaciones y las prácticas pertinentes para la conservación de los recursos zoogenéticos y su utilización sostenible y, cuando proceda, instituir políticas y medidas legislativas eficaces.

En esta declaración sólo se reconoce una tipología de conocimientos tradicionales que, de alguna manera, transita por los mismos caminos de las normas antes analizadas, pues se convoca a los Estados

45. Pese a este análisis, constituye un impedimento la eliminación del privilegio del agricultor, recogida en el Convenio upov, cuestión que dificulta la libre utilización de las semillas y especies vegetales necesarias para la alimentación, cultivo y medicinas de las comunidades indígenas y locales. Este tratado, pese a su intención inicial de constituir un sistema generalizado de acceso mutuo a todos los recursos fitogenéticos para la alimentación y la agricultura, cedió ante las fuerzas pujantes de los países desarrollados que se opusieron a toda disposición que limitara el derecho de las empresas a continuar privatizando los recursos genéticos, en especial su derecho a patentarlos. Asimismo, algunos países en desarrollo apostaron por la limitación del ámbito de alcance y aplicación del tratado, en aras de preservar las oportunidades comerciales percibidas en función de su carácter de proveedores de genes individuales para el mercado mundial. Sin embargo, hay que destacar que ofrece otras opciones de intercambio internacional de semillas en relación con las reconocidas en el CDB. Véase GRAIN. Re-SITUATING THE BENEFITS FROM BIODIVERSITy. (2005). Disponible en www.grain.org/ seedling/?id $=327$.

46. Aprobada en la Conferencia Técnica Internacional sobre los Recursos Zoogenéticos para la Alimentación y la Agricultura. DeCLARACIÓN DE INTERLAKEN SOBRE LOS RECURSOS ZOOGENÉTIcos. Septiembre 7 de 2007. Disponible en www.fao.org/docrep/010/ a1404s/a1404s00.HTM.

47. Disponible en el sitio http://www.fao.org/3/a-a1404s.pdf a adoptar determinados patrones en sus normas internas sin identificar el cómo.

\section{Convención de las Naciones Unidas de lucha} contra la desertificación en los países afectados por sequía grave o desertificación (1994)

Esta convención establece en su artículo 18.2 b cómo las partes protegerán, promoverán y utilizarán en particular las tecnologías, los conocimientos, la experiencia y las prácticas tradicionales y locales pertinentes, y con este fin, se ocuparán de:

Garantizar que esas tecnologías, conocimientos, experiencia y prácticas estén adecuadamente protegidos y que las poblaciones locales se beneficien directamente, de manera equitativa y según lo convenido por mutuo acuerdo, de cualquier uso comercial que se haga de ellos o de cualquier otra innovación tecnológica resultante. ${ }^{48}$

En este sentido, hay una referencia a la figura que se enmarca en lo relativo a las acciones para combatir dicha desertificación. Se prevé además en el artículo 6.b del "Anexo II" la confección de instrumentos de recopilación de conocimientos y experiencias, con el fin de ponerlos a disposición de los interesados, cuestión que constituye un reconocimiento importante en esta materia.

8. Declaración de las Naciones Unidas sobre los derechos de los pueblos indígenas ${ }^{49}$

La declaración aprobada por la Asamblea General en el 2007 establece la facultad de los pueblos indígenas de administrar sus conocimientos tradicionales, experiencias e innovaciones, así como la propiedad intelectual que con todo lo anterior se relaciona, al mismo tiempo que pone en manos de los Estados la responsabilidad de legislar en función de la protección de estas creaciones intelectuales en conjunto con las comunidades indígenas. Se trata de un reconocimiento amplio e integral, que si bien no tiene carácter vinculante, manifiesta la voluntad política de los Estados firmantes.

48. U.N. CONVENCIÓN DE LAS NACIONES UNIDAS DE LUCHA CONTRA LA DESERTIFICACIÓN EN LOS PAÍSES AFECTADOS POR SEQUÍA GRAVE O DESERTIFICACión. (1994). Disponible en http://es.wikisource. org/wiki/ Convenci\%C3\%B3 n_de_las_Naciones_Unidas_de_ Lucha_contra_la_Desertificaci\%C3\%B3n

49. Cf. Artículo 31. 
En este instrumento, se abordan los conocimientos tradicionales de forma global. De ahí la inclusión de los conocimientos tradicionales del sector agrícola, los cuales son los respectivos derechos que asisten a estas comunidades.

9. Convención de la unEsCo para la Salvaguardia del Patrimonio Cultural Inmaterial ${ }^{50}$

En esta convención, se destaca la inexistencia de un instrumento internacional capaz de vincular a los Estados en lo referido a la protección del patrimonio inmaterial, de ahí que este constituya su objetivo principal. Se persigue además que los Estados adopten normas internas que garanticen la protección del patrimonio inmaterial y cooperen en función de aunar esfuerzos a nivel regional e internacional.

Dicha convención comprende de forma general todas las creaciones fruto del intelecto humano sin particularizar, lo que de alguna manera es positivo ya que engloba los conocimientos tradicionales en su generalidad. No obstante, es preciso tener en cuenta que su naturaleza atípica impone determinadas incompatibilidades con otras creaciones de esta índole, por tanto, a juicio de la autora, se ha de ser cuidadoso en el abordaje del tema en los ordenamientos internos.

\section{Convención de la unEsco sobre la Protección} y la Promoción de la Diversidad de las Expresiones Culturales $^{51}$

Desarrollada en el 2005, establece como protección la adopción de medidas encaminadas a la preservación, salvaguardia y enriquecimiento de la diversidad de las expresiones culturales. Asimismo, hace referencia a la relación entre la difusión de los conocimientos tradicionales y la protección de las expresiones culturales tradicionales, al reconocer que la diversidad de expresiones culturales (comprendidas las expresiones culturales tradicionales) es un factor importante que permite a los pueblos y a las personas expresar y compartir con otros sus ideas y valores.

Resulta interesante en esta convención la referencia a la transmisión del conocimiento, lo cual es precisamente aquello que se necesita a fin de hacer frente a muchos de los problemas que hoy afectan a los pueblos, tales como la falta de alimentos o el

50. Véase Convención de la unEsco para la Salvaguardia del Patrimonio Cultural Inmaterial. (Octubre 17 de 2003). Disponible en http://www.unesco.org/confgen/2003/intangible/es.

51. Véase Convención de la unEsco sobre la Protección y la Promoción de la Diversidad de las Expresiones Culturales. (2005). Disponible en http://portal.unesco.org/culture/es/ev.php- cambio climático. Es posición de la autora que uno de los mecanismos más importantes en torno a la protección de los conocimientos tradicionales es su socialización, siempre y cuando no tengan un carácter confidencial.

11. Unión Internacional para la Protección de las Variedades Vegetales (UPOv)

El sistema de la upov de protección de las variedades vegetales surgió con la adopción del Convenio Internacional para la Protección de las Obtenciones Vegetales ${ }^{52}$ en el seno de la Conferencia Diplomática del 2 de diciembre de 1961, en París. Dicho Convenio ha sido objeto de revisión en 1972, 1978 y 1991, fortaleciendo cada vez los derechos de los obtentores.

Para que las variedades vegetales generen derechos exclusivos se exigen cuatro requisitos: distintividad, homogeneidad, estabilidad y novedad desde el punto de vista comercial.

Se trata de un sistema sui generis que difiere del sistema de patentes en cuanto exige otros requisitos y el objeto de protección es diferente. No obstante, no existe referencia a la protección de los conocimientos asociados a estas variedades, es decir, el procedimiento para la obtención de la variedad no es protegible. Cuestión distinta lo es el hecho de brindar protección a aquellas variedades resultantes de la utilización de conocimientos tradicionales, siempre que reúnan los requisitos legales establecidos. En este supuesto se manifestaría una protección indirecta de la institución objeto de análisis.

\section{Organización Mundial de Propiedad Intelectual (OMPI)}

El interés por el tema tiene sus inicios hacia 1998. Su punto de partida fue el desarrollo de dos mesas redondas sobre los conocimientos tradicionales y nueve misiones exploratorias sobre los conocimientos tradicionales, las innovaciones y la creatividad. Las misiones tuvieron como objetivo conocer los intereses y las necesidades de los poseedores de tales saberes y experiencias..$^{53}$

De esta manera, fue organizada en Chiang Rai, Tailandia, una reunión interregional que arrojó "una Política y un Plan de Acción para el Futuro", entre

52. Véase Convenio Internacional para la Protección de las Obtenciones Vegetales. (1961). Disponible en www.upov.int. 53. Véase OMpI. Documento OMPI/GRTKF/IC/1/3. (2001). Pág. 11. Disponible en www.wipo.int. 
los que se encontraba el establecimiento del Comité Intergubernamental, cuyo fin mediato sería centrarse en cuestiones tales como:

1. Los principios y objetivos de la protección de los conocimientos tradicionales.

2. Las relaciones existentes entre el sistema oficial de propiedad intelectual y los sistemas jurídicos consuetudinarios de las comunidades locales e indígenas.

3. Las formas de titularidad colectiva que puedan existir.

4. Los medios para resolver problemas jurídicos y administrativos en relación con el tema.

Son muchas las veces que ha sesionado este comité e innumerables los documentos que de ellas se han derivado; no obstante, no se ha logrado, según la autora, el objetivo principal: la aprobación de un instrumento internacional que unifique los objetivos y principios en torno a la protección y preservación de los conocimientos tradicionales, cuestión que será objeto de análisis a continuación.

\section{Ley tipo sobre el folklore de la OMPI/UNESCO ${ }^{54}$}

Esta ley establece algunas definiciones y criterios para la protección de obras del folklore. Se enumeran expresiones del folklore con fines ilustrativos; se establecen dos tipologías principales de actos frente a los cuales ha de brindarse protección (explotación ilícita y otras acciones perjudiciales); se especifican supuestos en los que no se precisa de autorización para el uso de las obras; se exige que se cite la fuente de las obras y se prevé el deber de designar representante de las comunidades, en aras de lograr el ejercicio de sus derechos. En lo relativo a las autorizaciones, se exhorta a los Estados a conformar tribunales que se ocupen de las apelaciones ante la denegación de autorizaciones.

En relación con el tema se aprobó también la recomendación sobre la salvaguardia de la cultura tradicional y popular, la cual fue fruto de la "Conferencia General de la 11" en su vigésimoquinta versión, reunión que tuvo lugar en París el 15 de

54. Esta ley tipo fue incluida por el informe del grupo de trabajo relativo a la protección del folklore aborigen de la OMPI/IUNESCO en 1981. Fue aprobada en 1982. Véase Delia Lipszyc, supra, nota 30. Págs. 96-98. Para conocer del proceso de aprobación y antecedentes de esta norma, véase Óscar Alberto Pérez Peña. Protección DE LA CULTURA POPULAR POR EL DERECHO DE AUTOR: ESPECIAL referencia a Cuba. Tesis de Doctorado en Ciencias Jurídicas. Universidad de La Habana. (2012). Pág.12. noviembre de 1989. En ella se recogen un conjunto de medidas garantes de la protección de las obras del folklore nacional, se definen las expresiones cultura y popular - por vez primera-, y se establecen seis puntos de acción a cumplir por los Estados. ${ }^{55}$

En este sentido, cabe destacar cómo ha sido un reclamo por parte de los países que pertenecen a la OMPI la elaboración de un tratado internacional que aglutine todo lo concerniente al tema, de manera que se unifique su tratamiento en los diferentes ordenamientos jurídicos.

14. Tendencias en el marco de la OMPI en relación con la protección de los conocimientos tradicionales no artísticos

El siguiente análisis desarrollado por la autora obedece a lo avanzado hasta la fecha en el seno del Comité Intergubernamental sobre Propiedad Intelectual y recursos genéticos, conocimientos tradicionales y expresiones culturales tradicionales (CIG), ${ }^{56}$ en lo referido a la protección de los conocimientos tradicionales strictu sensu. No atañe a las obras de la cultura popular tradicional y al acceso a los recursos genéticos, lo que responde a la división que en el seno del comité ha tenido lugar con el fin de abordar estas temáticas, de ahí que existan estudios y propuestas independientes para cada una de ellas.

En lo que concierne a los postulados que han de guiar la protección, se resaltan los siguientes:

Reconocer el valor de los conocimientos tradicionales; promover la sensibilización y el respeto de los sistemas de conocimientos tradicionales; promover la preservación de los conocimientos tradicionales; tener en cuenta y actuar en concordancia con los acuerdos y procesos internacionales pertinentes; promover el acceso a los conocimientos y salvaguardar el dominio público; catalogar y conservar los conocimientos tradicionales; promover la innovación; proporcionar nuevas normas y disciplinas; relación con el uso consuetudinario al no limitar la creación, ni el uso, la transmisión, el intercambio y el desarrollo consuetudinarios..$^{57}$

Es criterio de la autora que debería incluirse lo relativo a la divulgación de los conocimientos

55. Véase Delia Lipszyc, supra, nota 30. Págs. 99-103

56. Véase OMPI. LA PROTECCIÓN DE LOS CONOCIMIENTOS TRADICIONALES: PROYECTO DE ARTÍCULOS. REV. 2 EN ANEXO DE DOCUMENTO WIPO/GRTKF/IC/28/5. Disponible en www.wipo.int. 57. Id. 
tradicionales en aquellos casos que sea pertinente, ya que esta divulgación es en ocasiones la propia forma de preservación y conservación, aunque puede entenderse que se deriva de otros postulados ("Promover el acceso a los conocimientos y salvaguardar el dominio público" ${ }^{\prime 58}$ ); no obstante, existe la necesidad de explicitar este particular.

En lo que respecta a los objetivos de la protección, es aconsejable incluir que la protección no alcance sólo los conocimientos tradicionales per se, sino también a los productos que se derivan de la aplicación de conocimientos tradicionales, ya que estos no siempre pueden ser objetos de protección de los derechos de propiedad industrial.

En el marco de la definición de términos, dado el objeto de estudio de la presente investigación, resulta interesante la definición de conocimientos tradicionales manejada: "los conocimientos especializados, capacidades, innovaciones, prácticas, enseñanzas y aprendizajes de comunidades locales e indígenas, pueblos o Estados" ${ }^{39}$, ya que de ella escapan los conocimientos tradicionales de carácter individual, pues se insiste en que son los conocimientos de las localidades, pueblos o Estados, de las colectividades.

La definición del término Uso no autorizado ("es el uso de conocimientos tradicionales protegidos sin el permiso del titular de los derechos"60) no escapa del análisis, pues hace alusión a la titularidad. ${ }^{61}$ Término estrechamente vinculado con los derechos de propiedad intelectual, de ahí la opción de usar otros vocablos que ofrece el propio texto, tales como poseedor o beneficiario.

En relación con la materia objeto de protección, se reafirma la posición de excluir los conocimientos tradicionales individuales, al referirse a su creación y mantenimiento en contextos colectivos. Asimismo, se establece como requisito la transmisión intergeneracional, excluyendo así las transmisiones susceptibles de producirse entre personas de una misma generación.

En el tema de los beneficiarios de la protección, ${ }^{62}$ se entiende que hace referencia a los beneficiarios

58. Id.

59. Id.

60. Id.

61. "Titular: Quien goza legítimamente de un derecho declarado o reconocido a su favor". Véase Manuel Ossorio, supra, nota 26. Pág. 947.

62. Si bien cuando se hace referencia a protección, se entiende que se aluden los derechos de propiedad industrial, de los cuales no es beneficiaria la humanidad, existen otras formas de protección con las cuales el beneficio sí es general. Por ejemplo, la divulgación mediante los documentos de patentes o la confección de bases de inmediatos, cuestión que lleva a un análisis en torno al legado cultural de estas comunidades en relación con el resto de la humanidad. Enfocarlo de esta forma da al traste con el valor que se le quiere atribuir; resulta más apropiado el uso del término beneficiarios inmediatos, pues de lo contrario se debe incluir al público en general en la definición del término.

En torno al ámbito de protección, la referencia exclusiva al sistema nacional e internacional con respecto a la participación de los beneficios deja al margen al sistema consuetudinario, aspecto que se debe valorar en futuras reuniones ya que el ámbito nacional no tiene por qué comprender el derecho consuetudinario.

Es necesario resaltar que la posición global que se asume en este contexto está situada desde la perspectiva de conceder derechos o reconocer facultades de carácter colectivo - de allí los términos empleados-, lo que a juicio de la autora constituye un desacierto, ya que al tratarse de unas pautas internacionales deben ser contempladas todas las opciones posibles, así como se ha de tener una vocación de generalidad en su delimitación de manera que facilite su aplicación.

Lamentablemente notable resulta el hecho de excluir de la protección los conocimientos tradicionales muy difundidos y aquellos pertenecientes al dominio público, ya que precisamente el reconocimiento de la fuente de los conocimientos tradicionales es parte importante de esa protección. De manera que esto ha de existir siempre, aun cuando sean muy difundidos o formen parte del dominio público. Por ende, esta exclusión no debería tomarse en consideración en una futura regulación internacional del tema.

En el orden positivo y con acierto, en lo referido a las medidas complementarias se conjugan elementos del sistema nacional y consuetudinario, en el cual ocupa un espacio relevante el uso de bases de datos a fin de catalogar y preservar estos conocimientos. Dentro de este grupo de medidas se incluye la institución del secreto empresarial, a tenor de la descripción que se hace de los requisitos a tener en cuenta para considerar conocimientos tradicionales como tales. No obstante, resulta oportuno llamar la atención sobre el carácter que ha de tener una información con el fin de ser considerada como secreto empresarial. El Acuerdo sobre los ADPIC exige que la información protegida a través del secreto ha de ser

datos de conocimientos tradicionales, que si bien no constituyen derechos, forman parte de lo que se conoce como protección preventiva, ya que impide la apropiación indebida y usos no autorizados, así como la pérdida por la falta de uso o divulgación. 
comercialmente valiosa; sin embargo, en el ámbito de los conocimientos tradicionales, no se hace alusión en los debates a este valor comercial, sino más bien cultural o espiritual, lo que no es excluyente a juicio de la autora, pero tampoco es una generalidad la presencia del valor comercial (de allí que habrá de precisarse este particular).

Las sanciones, recursos y el ejercicio de los derechos comprenden las medidas en frontera, sanciones y recursos en lo penal civil y administrativo. Se precisa en este particular que los procesos tendrán como carácter distintivo el hecho de no constituir una carga para los poseedores, y las sanciones tendrán como base no sólo la norma nacional, sino también la consuetudinaria.

La obligación de divulgación de la fuente del conocimiento tradicional ha de ser base para la protección, pues su inclusión en los debates resulta oportuna ya que permite constatar la existencia de consentimiento a partir de la revelación de la fuente y es también una forma de reconocer el aporte de las comunidades.

La facultad de establecer administraciones encargadas de velar por los derechos también constituye un aspecto positivo, más aún si se tienen en cuenta los sistemas consuetudinarios (esto no debe ser optativo sino obligatorio). Se trata de la existencia de oficinas nacionales o departamentos dentro de las oficinas nacionales de propiedad industrial $\mathrm{u}$ otros entes administrativos, responsables de atender las cuestiones relativas a los derechos de las comunidades. Es la posibilidad de dar seguimiento a la situación de estos derechos como se realiza con otras instituciones de la propiedad industrial. ${ }^{63}$

En lo concerniente a las limitaciones, se adopta el criterio de depositar en manos de los Estados la facultad de determinar cuáles quedarán comprendidas en la norma nacional, con la acotación de no impedir el uso de los conocimientos tradicionales, reflejar la fuente y no afectar a sus poseedores. Asimismo, se prohíbe el uso de esta institución en aquellos casos de daño irreparable.

No obstante, son reflejadas las limitaciones a los derechos de carácter general que se observan con frecuencia en las normas de propiedad intelectual,

63. En el caso de la Ley N. ${ }^{\circ} 7788$ de Costa Rica (Ley de Biodiversidad), posee un conjunto de artículos relacionados con la protección de los conocimientos tradicionales, entre los que destaca la existencia de una Oficina Técnica (artículos 63-65), amén de la autoridad competente por parte de las comunidades poseedoras de conocimientos tradicionales. En igual sentido el artículo 86 de la Ley de Diversidad Biológica de Venezuela establece la responsabilidad de la Oficina Nacional de la Diversidad Biológica de proteger los conocimientos de las comunidades indígenas y locales. Véase Manuel Ruiz Muller, supra, nota 25. Págs. 103, 104 y 138. tales como el uso con fines de enseñanza, investigativos no comerciales, emergencia nacional, y creación de una obra original a partir de ese conocimiento tradicional. A esto se suma la regulación de aquellos supuestos de libre utilización (los creados de forma independiente, derivados de otra fuente $\mathrm{u}$ obtenidos fuera de la comunidad), los supuestos de no apropiación indebida (obtención a partir de documento impreso, obtención a través de consentimiento de los poseedores y obtención a través de la entidad administrativa destinada a la gestión de los conocimientos), y la posibilidad de eximir de protección los métodos diagnósticos, terapéuticos y quirúrgicos para el tratamiento de seres humanos o animales, así como los conocimientos tradicionales que están a disposición del público.

En cuanto a la duración de la protección estará en función de lo que decidan los Estados, siempre que los conocimientos cumplan con los requisitos que los distinguen como tal.

En el terreno de las formalidades para la protección, se encuentran en discusión dos posiciones (la de su exigencia o no), cuestión que debe ser objeto de revisión pues no todos los conocimientos tradicionales tienen las mismas características. De allí que debe ofrecerse una regulación flexible que permita la exigencia de formalidades para determinados supuestos, como por ejemplo aquellos que corran el riesgo de perderse; en tal sentido la alternativa ofrecida resulta más apropiada.

Se promueve también la aplicación de regulaciones en el terreno de los conocimientos tradicionales sin afectación de derechos de terceros. En igual sentido, se establecen previsiones en los supuestos de utilización o preparación para la utilización anterior a la adopción de algún instrumento internacional, a saber, la continuidad en la utilización a cambio de una compensación y el cumplimiento de las condiciones de acceso.

Se enarbola como necesaria la cooperación entre los derechos de propiedad intelectual asociados a conocimientos tradicionales y los instrumentos jurídicos internacionales, así como la cooperación transfronteriza para aquellos supuestos en los que dos Estados o más compartan la posesión de iguales conocimientos.

Sobre la base de los debates que tienen lugar en el seno del CIG, puede observarse un profundo interés por la protección de los conocimientos tradicionales, inclinado por supuesto hacia los mecanismos de propiedad intelectual (sin dejar de mencionar vías alternativas y consuetudinarias). De igual manera, se destaca el uso indistinto de términos tales como 
beneficiarios, poseedores, titulares y propietarios, cuestión que debe uniformarse en aras de esclarecer el estatus legal de estas comunidades en relación con sus conocimientos tradicionales. En otro sentido, resulta inexcusable la no inclusión de los conocimientos tradicionales individuales, ya que son también manifestaciones de la institución.

El punto de partida para el abordaje o tratamiento legal de los conocimientos tradicionales debe girar en torno a los siguientes puntos:

1. El respeto de los sistemas de conocimientos tradicionales y su preservación.

2. Una distribución justa y equitativa de los beneficios derivados de la utilización de los conocimientos tradicionales.

3. Un aumento de la utilización de los conocimientos tradicionales.

4. La creación de sistemas económicos y jurídicos para los titulares de los conocimientos tradicionales y sus comunidades.

5. La protección de los conocimientos tradicionales en el contexto de la conservación de la diversidad biológica.

6. El acuerdo sobre los principios y objetivos de la protección de los conocimientos tradicionales. En este punto los Estados hicieron diversas propuestas y quedaron los siguientes:

- La comprensión de las relaciones existentes entre el sistema oficial de propiedad intelectual y los sistemas jurídicos consuetudinarios que se aplican a los conocimientos tradicionales en las comunidades locales e indígenas, lo que se evidencia en la referencia expresa en declaraciones e instrumentos internacionales. ${ }^{64}$

- El abordaje de la creación, innovación y titularidad colectiva en ciertos sistemas de conocimientos tradicionales, en razón a la necesidad de las comunidades titulares de conocimientos tradicionales de gozar de derechos colectivos o comunitarios.

La adopción de medios para la solución de problemas jurídicos y administrativos relacionados con los conocimientos tradicionales regionales engloba una serie de aspectos a tener en cuenta. Entre estos se

64. Cf. Artículo 8 del Convenio 169 de la Organización Internacional del Trabajo; Artículos 12 y 33 del Proyecto de Declaración de las Naciones Unidas sobre los Derechos de las Poblaciones Indígenas (1994); y el Principio 4 de los Principios y Directrices para la Protección del Patrimonio de los Pueblos Indígenas de la Subcomisión de las Naciones Unidas de Prevención de Discriminaciones y Protección a las Minorías. encuentran: la determinación de la competencia jurídica de las autoridades nacionales o regionales para autorizar la utilización de conocimientos tradicionales integrantes del patrimonio nacional de varios países; el establecimiento de reglamentos y normas administrativas que regulen los procedimientos de autorización para varias comunidades e incluso países; la definición de posibles soluciones en situaciones de conocimientos tradicionales compartidos por países en los que alguno de ellos no sea parte del tratado internacional relativo al tema; la distribución de beneficios económicos derivados de la utilización de conocimientos tradicionales entre los diferentes implicados; la determinación del carácter nacional o regional de un conocimiento tradicional; y la solución de controversias que surjan en relación con lo antes referido.

15. Declaración de los derechos de las campesinas y los campesinos de la Vía Campesina (Movimiento Campesino Internacional) ${ }^{65}$

En su artículo v hace referencia al "Derecho a las semillas y al saber y práctica de la agricultura tradicional", ${ }^{66}$ lo cual engloba a su vez un grupo de derechos, entre los cuales tiene particular importancia el "Derecho a conservar y desarrollar su conocimiento local sobre agricultura, pesca y cría de ganado", así como el "Derecho a escoger sus propios productos, variedades, cantidades, calidades y métodos de prácticas de la agricultura, la pesca o la cría de ganado, individual o colectivamente". ${ }^{67}$ Ambos reafirman el valor y la importancia de los conocimientos tradicionales agrícolas. En igual sintonía se encuentra el artículo $\mathrm{XI}^{68}$ al reconocer el "Derecho a la pre-

65. Véase Colectivo de autores. Manual para juezas y JUECES SOBRE LA PROTECCIÓN DE LOS DERECHOS DE LAS CAMPESINAS Y CAMPESINOS. Oficina para América Latina de la Coalición Internacional para el Hábitat. (2013). Pág. 268.

66. Id. "1. Derecho a determinar las variedades de semillas que se quieren plantar. 2. Derecho a rechazar las variedades de plantas que consideren peligrosas económica, ecológica y culturalmente. 3. Derecho a rechazar el modelo industrial de agricultura. 4. Derecho a conservar y desarrollar su conocimiento local sobre agricultura, pesca y cría de ganado. 5. Derecho al uso de instalaciones agrícolas, de pesca y de cría de ganado. 6. Derecho a escoger sus propios productos, variedades, cantidades, calidades y métodos de prácticas de la agricultura, la pesca o la cría de ganado, individual o colectivamente. 7. Derecho a utilizar sus propias tecnologías o la que escojan con el fin de proteger la salud humana y el medio ambiente. 8 . Derecho a cultivar, intercambiar o vender sus semillas. 9. Derecho a la soberanía alimentaria".

67. Id.

68. Engloba los siguientes derechos: 1. Derecho a un medioambiente limpio y saludable. 2. Derecho a preservar el medioambiente de acuerdo con su saber y sus conocimientos. 3. Derecho a rechazar 
servación del medio ambiente" sobre la base de sus conocimientos tradicionales.

\section{CONCLUSIONES}

Con el propósito de definir los conocimientos tradicionales agrícolas es preciso tener en consideración un grupo de elementos, a saber: la tipología, el carácter individual o colectivo en relación con sus poseedores, el contexto en que surgen y se transmiten, así como la impronta temporal de la que son objeto.

Si bien los conocimientos tradicionales agrícolas son bienes inmateriales, su carácter atípico hace que presenten un grupo de diferencias con respecto al resto de los bienes inmateriales. Cuestión que no los aparta de este grupo.

Existe un grupo significativo de instrumentos internacionales que abordan de una forma $u$ otra la institución de los conocimientos tradicionales; sin embargo, presentan algunas limitaciones. Unos lo hacen de forma parcial - ya sea referido a una tipología específica o a un grupo de poseedores-, mientras que otros no tienen carácter vinculante o la regulación que ofrecen no establece pautas a seguir, de manera que no siempre resultan idóneos para los conocimientos tradicionales del sector agrícola.

En el plano internacional existen importantes debates. En el seno del Cig de la OMPI, se dan en torno a los objetivos y principios que han de orientar la protección de los conocimientos tradicionales, por ejemplo. No obstante, existen algunos elementos sobre los que deben detenerse con cautela los Estados, como es el supuesto de no incluir los saberes individuales y la falta de uniformidad en torno al uso de los términos: poseedores beneficiarios y titulares de conocimientos tradicionales.

\section{REFERENCIAS}

Antonio Aja Díaz. Desigualdades y migraciones internacionales: una serpiente que se muerde la cola. Revista Temas 45. Enero-marzo de 2006.

Andryth Aguilar Villán. Los SECRETOS EMPRESARIALES COMO parte de la Propiedad Industrial. ReFLEXIONES EN EL CASO Cubano. Tesis de Doctorado en Ciencias Jurídicas. Universidad de La Habana. (2008).

cualquier forma de explotación que cause daños medioambientales. 4. Derecho a convenir y reclamar compensaciones por los daños medioambientales. 5. Derecho a ser indemnizados por la deuda ecológica y por el despojo histórico y actual de sus territorios. Id.
Bertha Luz Alvarado Castro. Rescate Del Conocimiento tradicional. Desde la perspectiva de la nueva Legislación Forestal en Perú. Ed. Dirección General Forestal y de Fauna Silvestre. Ministerio de Agricultura (s/a).

Colectivo de autores. Manual para juezas y jueces soBRE LA PROTECCIÓN DE LOS DERECHOS DE LAS CAMpesinas y CAMPESINOS. Ed. Oficina para América Latina de la Coalición Internacional para el Hábitat. (2013).

U.N. Convención de las Naciones Unidas de lucha CONTRA LA DESERTIFICACIÓN EN LOS PAÍSES AFECTADOS POR SEQUÍA GRAVE O DESERTIFICACIÓN. (1994). Disponible en http://es.wikisource.org/wiki/Convenci\%C3\%B3n_de_las_Naciones_Unidas_de_Lucha_ contra_la_Desertificaci\%C3\%B3n

Conferencia Técnica Internacional sobre los Recursos Zoogenéticos para la Alimentación y la Agricultura. DECLARACión de INTERLAKen SOBRe LOS ReCURSOS Zoogenéticos. (Septiembre 7 de 2007). Disponible en www.fao.org/docrep/010/a1404s/a1404s00.HTM.

Convención de la unesco sobre la Protección y la Promoción de la Diversidad de las Expresiones Culturales. (2005). Disponible en http://portal.unesco.org/culture/es/ev.php-.

Convención de la unesco para la Salvaguardia del Patrimonio Cultural Inmaterial. (Octubre 17 de 2003). Disponible en http://www.unesco.org/confgen/2003/ intangible/es. (10 agosto, 2014).

Convenio Internacional para la Protección de las Obtenciones Vegetales. (1961). Disponible en www.upov.int.

Dánice de la C. Vázquez D’Alvaré. La Competencia desLeal en el mercado cubano. Tesis de Doctorado en Ciencias Jurídicas. Universidad de La Habana. (2004).

Delia Lipszyc. Derecho de Autor y derechos conexos. Tomo I. Editorial Félix Varela. (2001).

Decisión 486 de 2000. [Comunidad Andina]. Que establece el Régimen Común sobre Propiedad Industrial. Septiembre 14 de 2000.

George Hobson. Traditional Knowledge is SCIEnce. Disponible en http://www.carc.org/pubs/v20no1/ science.htm.

GRAIN. RE-SITUATING THE BENEFITS FROM BIODIVERSITY. (2005). Disponible en www.grain.org/seedlin$\mathrm{g} /$ ? id $=327$

Gustavo Capdevila. Indigenous PEOPLes DEFEND TRADItional KNOWLEDge. InterPress Third World News Agency. (2000). Disponible en www.forest.org/archive/general/indefkno.htm. 
Hermenegildo Baylos Corroza. Tratado DE Derecho INDUSTRIAL. Civitas. (1978).

John Mugabe. LA PRotección DE LA PROPIEDAd INTELECTUAL Y LOS CONOCIMIENTOS TRADICIONALES. UN ANÁLISIS DE LA ORIENTACIÓN DE LAS NORMAS DE POLÍTICA INTERNACIONAL. (1998). Disponible en http:// www.acts.or.ke.

Jorge Caillaux Zazzali y Manuel Ruiz Muller. La protección jurídica de los conocimientos tradicionales y sus desafíos. Anuario Andino de Derechos Intelectuales 1. 2004.

Ley de Protección del Patrimonio de los Aborígenes y los Isleños del Estrecho de Torres de Australia. 1984. Disponible en www.austlii.edu.au/au/legis/cth/consol_act/ aatsihpa1984549.txt.

Ley N. 27811 de 2002. Establece un Régimen Especial de Protección de los Conocimientos Colectivos de los Pueblos Indígenas Asociados a la Diversidad Biológica. (Julio 24 de 2002).

Lilian Álvarez Navarrete. Derecho DE ¿AUtor? El DebATe DE HOY. Ciencias Sociales. (2006).

Marta Moreno Cruz y Emilia Horta. Selección de LeCturas de Propiedad Industrial. Tomo I. Editorial Félix Varela. (2003).

Manuel Ruiz Muller. LA PROTECCIÓN JURÍDICA DE LOS CONOCIMIENTOS TRADICIONALES: ALGUNOS AVANCES POLÍTICOS Y NORMATIVOS EN AMÉRICA LATINA. UICN, BMZ, SPDA (2006).

Manuel Ossorio. DiCCIONARIO DE CIENCIAS JURÍDICAS POLÍ́TICAS Y SOCIALES. Datascan. (s/a).

Martin Khor. El SAqueo del Conocimiento. Propiedad INTELECTUAL, BIODIVERSIDAD, TECNOLOGÍA Y DESARROLLO SOSTENIBLE. Icaria Editorial. (2003).

Natalia Tobón Franco. Un enfoque diferente para la protección de los conocimientos tradicionales de los pueblos indígenas. REvista Estudios Socio-JuRídicos 1. (Enero-junio de 2007). Págs. 96-129.

ompi. Panorama de las Cuestiones globales DE LA Propiedad INTElectual: LA PROTECCión DEL FOLCLORE, LOS CONOCIMIENTOS TRADICIONALES Y LA BIODIVERSIDAD. (2000). Disponible en www.wipo.int.

OMPI. DOCUMENTO OMPI/GRTKF/IC/1/5. (2001). Disponible en www.wipo.int.

OMPI. Documento WIPo/GRTKF/IC/3/9. (2002). Disponible en www.wipo.int OMPI.

OMPI. Documento PR/2011/682. (2011). Disponible en www.wipo.int.

OMPI. DoCumento OMPI/GRTKF/IC/7/7. (2004). Disponible en www.wipo.int.

OMPI. DoCUmento OMPI/GRTKF/IC/1/3 . (2001). Disponible en www.wipo.int.

OMPI. LA PROTECCIÓN DE LOS CONOCIMIENTOS TRADICIONALES: PROYECTO DE ARTÍ́CULOS. REV. 2 EN ANEXO DE DOCUMENTO WIPO/GRTKF/IC/28/5. Disponible en www.wipo.int.

Orlando Rivero Valdés. Temas de Derechos Reales. Editorial Félix Varela. (2007).

Óscar Alberto Pérez Peña. Protección de la Cultura POPULAR POR EL DERECHO DE AUTOR: ESPECIAL REferencia a Cuba. Tesis de Doctorado en Ciencias Jurídicas. Universidad de La Habana. (2012).

Protocolo de Nagoya. (Octubre 29 de 2010). Disponible en en www.cbd.int.

Vicente Rapa Álvarez. Propiedad y otros Derechos soBRE BIENES. Facultad de Derecho, Universidad de La Habana. (1990).

u.n. Declaración Universal de Derechos Humanos. Artículo 27. (Diciembre 10 de 1948). Disponible en http://www.un.org/spanish/aboutun/hrights.html. 